\title{
Ten years of photonic games: lessons learnt
}

\section{Anne-Sophie Poulin-Girard, Geneviève Boudreau, Jérôme Landry, Audrey Veillette, Marc-André Guérard, et al.}

Anne-Sophie Poulin-Girard, Geneviève Boudreau, Jérôme Landry, Audrey Veillette, Marc-André Guérard, Gabrielle Thériault, Alexandre April, "Ten years of photonic games: lessons learnt," Proc. SPIE 10741, Optics Education and Outreach V, 107410C (14 September 2018); doi: 10.1117/12.2318985

EviE Event: SPIE Optical Engineering + Applications, 2018, San Diego, California, United States 


\title{
Ten Years of Photonic Games: Lessons Learnt Anne-Sophie Poulin-Girard ${ }^{* a}$, Geneviève Boudreau ${ }^{\mathrm{a}}$, Jérôme Landry, Audrey Veillette ${ }^{\mathrm{c}}$, Marc-André Guérard ${ }^{\mathrm{d}}$, Gabrielle Thériault ${ }^{\mathrm{e}}$ and Alexandre April ${ }^{\mathrm{f}}$ ${ }^{a}$ Centre for Optics, Photonics and Lasers, Université Laval, Canada; ${ }^{b}$ EXFO, Canada; ${ }^{\circ}$ Teraxion, Canada; ${ }^{\mathrm{d} E d d y f i, ~ C a n a d a ; ~}{ }^{\mathrm{e}} \mathrm{Gentec}$ Electro-Optics, Canada; ${ }^{\mathrm{f}}$ Cégep Garneau, Canada
}

\begin{abstract}
The Photonic Games are a yearly outreach event created in 2008 to spark teenagers' interest in light. In teams, high school students face several optics challenges designed to appeal to various abilities and interests. In the past 10 years, more than 1531 participants, 425 volunteers and 100 organizers have taken part in this unique student-organized activity. Following the 10th edition, past presidents took the time to reflect together on what they learnt from their experience and identified key elements explaining the long-lasting success of this initiative. Metrics have been defined to track the evolution of the activity's efficiency and are presented herein.
\end{abstract}

Keywords: STEM Outreach Programs, Optics and Photonics Awareness, Hands-on Experiments, Qualitative and Quantitative Metrics for Education

\section{10 YEARS OF SPARKING TEENAGERS' INTEREST ABOUT THE SCIENCE OF LIGHT}

Following the establishment of a joint OSA-SPIE student chapter at Université Laval in 2005, the sources of funding and the opportunities available through the student chapter structure were conducive to the development of new activities, more specifically in the field of education and outreach. First held in 2008, the Photonic Games [1] are a yearly event taking place on campus where teams of high school students compete in seven challenges designed to appeal to various talents and interests (see Table 1 for a complete list of the challenges). A hands-on workshop in the classroom precedes the main event.

The Photonic Games are a student-organized program that celebrated its $10^{\text {th }}$ anniversary in 2017. Proud of the success of this adventure that started with an ambitious idea 10 years ago, the presidents from the past editions share with the reader in this proceeding their reflections on lessons learnt from their experience. While this section describes the program, its goals and the format of the activity, the following sections address the participation and participant's profile, reflect on the competitive aspect of the activity and the importance of teamwork and list metrics that have been used to evaluate the success of the Photonic Games over the years. We hope that this look back on our program's strengths and weaknesses will help the reader establish long-term outreach and education activities to spark people's interest about the science of light.

\section{Lesson \#1: Dream big}

The president of the first edition refers to the Photonic Games as a major project. It was certainly true for the first organizing team, a group of graduate students who did not have much experience in planning large activities and in outreach in general. The president of the 2017 Photonic Games also believes in shooting for the stars. Even if it meant additional work, the 2017 organizing team decided to increase welcome more high school students to celebrate the tenth anniversary of the activity. Whether it means including new scientific content, increasing the number of participants, or implementing an innovative format, if something seems impossible at first but motivates people, there is no harm in evaluating the option.

\footnotetext{
*anne-sophie.poulin-girard@ copl.ulaval.ca
} 


\subsection{The goals of the program}

The Photonic Games have two main equally important goals that have remained unchanged since 2008. The assessment of the success of the activity with respect to these goals is described in section 5 .

In the vicinity of Université Laval, there is a high density of optics-related companies. For many years now, there has been a growing shortage of highly qualified personnel in the field of optics and photonics. For multiple reasons, including high school curriculum and college and university program structure, optics and photonics are not presented and seen as a training path, as opposed to physics or electrical engineering for example. The first goal of the Photonic Games is therefore to:

1. Increase awareness about optics and photonics among teenagers at a critical point in their studies. We hope that by discovering the field in an interactive way, they will consider an optics-related degree or training program.

STEM fields (Science, Technology, Engineering and Mathematics) are often seen as difficult topics in school, and in some underprivileged high schools, a very small portion of students choose science classes for this reason.

2. Create favorable conditions for STEM-related successes among underprivileged students to boost their selfconfidence and encourage them to stay in school. We also hope to open their minds to science and engineering as a career path or as a topic of interest.

\section{Lesson \#2: A common vision for long-lasting success and partnerships}

The Photonic Games have always stayed true to their identity by following their two main goals: (1) increasing awareness about optics and photonics so young people consider a career in the field and (2) increasing self-confidence in STEM for students from underprivileged communities by involving them in a fun and positive activity. Not only has this vision united organizers around the achievement of common goals, which has proven to be very powerful and motivating, but it also strengthened the identity of the activity. Coupled with the consistent format and the quality of the event, it contributed to long-lasting relationships with schools and on-going partnerships with industry and eased the recruitment of volunteers and organizers.

\subsection{The format}

During the main event, the teams compete in seven challenges that approach various topics that are already included in the official high school curriculum, like reflection, refraction and simple optical systems. However, other topics, such as birefringence, holography and optical fibers, are also included either in the challenges or during the workshop in the classroom that takes place a few weeks before the day of competition. The different challenges are also designed to appeal to various talents and skills: artistry, leadership, logic, general knowledge, strength and dexterity, interpersonal skills, etc. Since the students are on the campus for the event, we take this opportunity to conduct laboratory visits in various facilities including the Demonstration Laboratory, a dedicated facility for education and outreach within our research centre [2]. It is a great way to introduce students to a real research environment while still presenting appropriate concepts and demonstrations. Table 1 lists the various challenges and activities for each year since 2008. 
Table 1. Photonic Games challenges per year

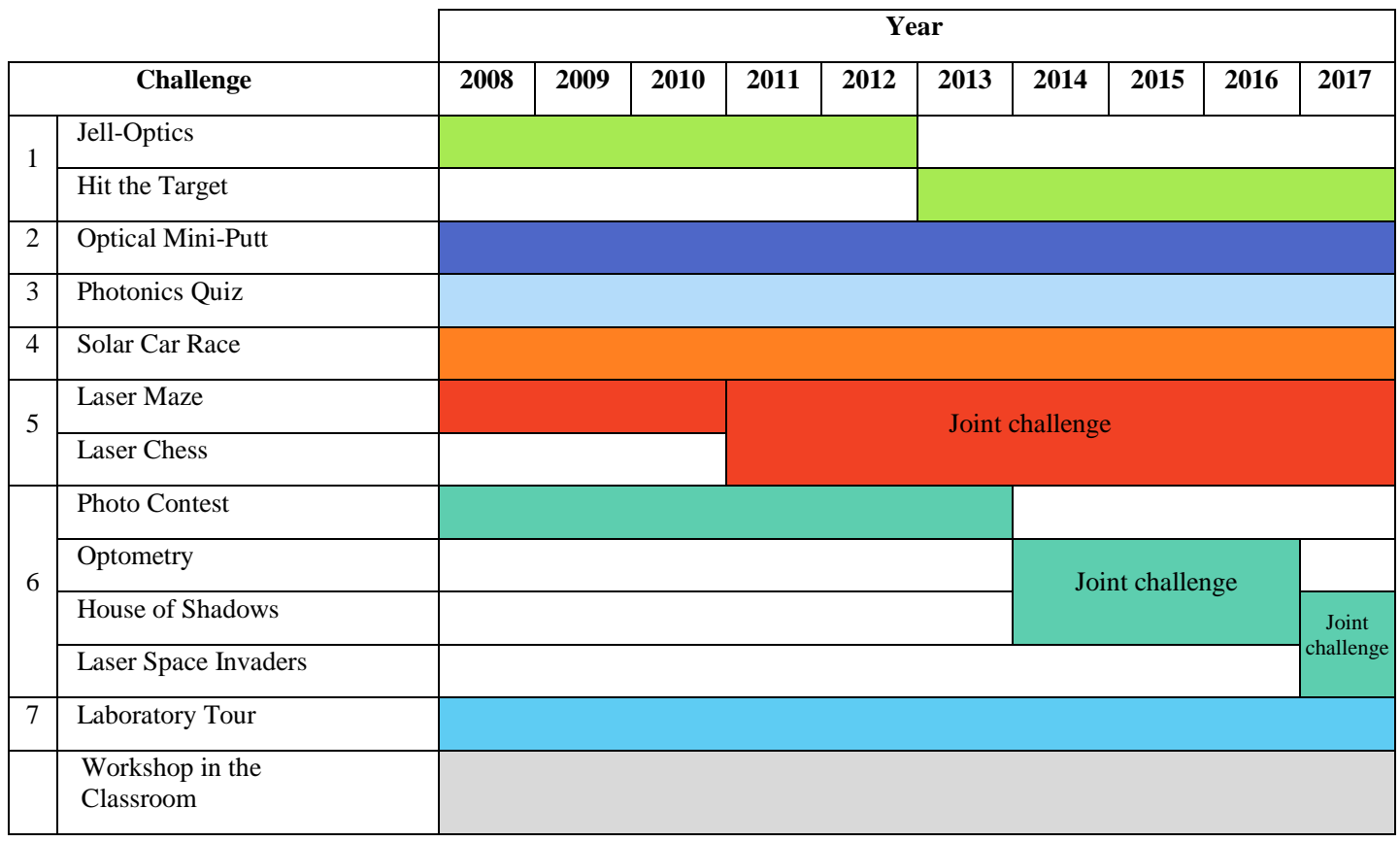

Lesson \#3: Perseverance and an open mind - move with the times

Some ideas are good on paper but do not translate well in real life situations. In our case, using Jell-O lenses in the Jell-Optics challenge fell into that category. After many years of perseverance with Jell-O, we switched to Hit the Target and started using acrylic lenses. We saw a significant improvement in students and volunteers feedback. Another example is the photo contest that slowly started to lose its appeal with the democratization of cellphones. It was replaced by a joint challenge. The Optometry setup was inspired by the undergraduate curriculum and the came up with the House of Shadows challenge during an informal brainstorm. The Laser Space Invaders challenge, that replaced the Optometry challenge, was the result of a collaboration with Gentec-EO that lent us equipment to create this video game-inspired activity. Longlasting programs have to evolve with respect to their core identity to ensure their success and longevity. Striking a balance between preserving tried-and-proven ideas and maintaining an open mind to change is key.

\section{10 YEARS OF STUDENT PARTICIPATION}

The Photonic Games' capacity in terms of participants is directly tied to the number of setups available. It also depends on the number of volunteers. Fig. 1 shows the number of participants, volunteers and teams over the years. From 2008 to 2012, the maximum capacity of the event was 28 teams ( 7 challenges with 4 identical setups each), accounting for between 112 and 140 students, depending on the year. One of the solutions to welcome more teams was to add two setups per challenge to reach a capacity of 42 teams. It led to the participation of 34, 40 and 38 teams between 2013 and 2015, for a total of 140, 192 and 179 students respectively. For the tenth anniversary, the organization decided to hold a two-day event, and welcomed 57 teams with the existing setups, for a total of 271 students.

The complex logistics of the Photonic Games, namely a very tight schedule and for the dynamics of moving teams between pavilions requires a large number of volunteers to manage the various challenges and accompany the teams. As it can be seen in Fig. 1, the ratio between number of teams and volunteers has remained smaller than 1, except for 2015. 


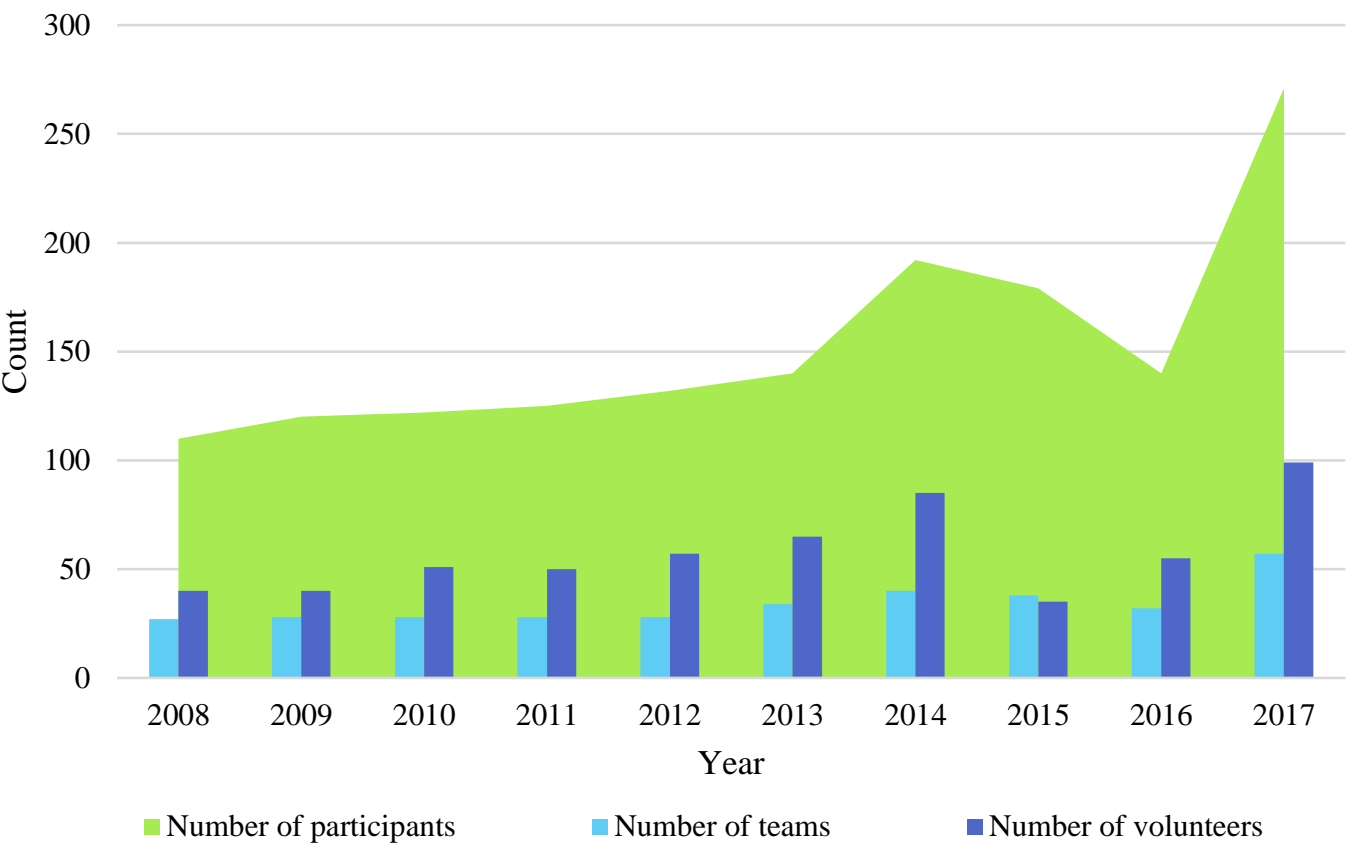

Figure 1. Number of participants, teams and volunteers per year

\section{Lesson \# 4: Manage your growth and learn to take a step back}

The smooth functioning of the Photonics Games depends on the volunteer's engagement. In 2015, while the number of volunteers was very low, the number of participants compared to other years. That year, the team relied on a common vision (lesson \#1) to find their motivation. The strategy for 2016 was to moderately decrease student participation to the level it was in 2013 while involving more volunteers in the main event. This step back was essential to allow for a future increase in participants.

Over the years, more and more schools have been invited to participate in the Photonic Games. Fig. 2 shows the number of participants for each school. A.S. Johnson High School was invited to attend the activity in 2010. The students of this school do not have the opportunity to participate in activities often because of the small number of students (only six in grade 11 science curriculum), their location and the fact that the teaching language is not French. In 2011, a fifth school was invited because fewer and fewer students were involved in the science curriculum in the participating schools. The increase in capacity in 2013 resulted in a sixth school being invited in 2014. In 2017, seven schools participated in the Photonic Games, for a grand total of nine schools over the years. This accounts for 1531 participants in 10 years.

\section{Lesson \# 5: Learn to deal with certainties and uncertainties}

Each year, the teachers trusted us to have their students miss a day of school to attend our event. One thing has always been a certainty for us: once the schools were invited, we had to deliver a great activity to honor that trust. In addition, independently of the level or preparedness, the deadline is inflexible. The Photonic Games also had their share of uncertainties. One past president mentioned that in 2012, a school contacted the organization to secure their participation before the school year even started. Given so much enthusiasm, we could not refuse. The team invited them before all the sponsors were confirmed, which put additional pressure on the organization. We have also encountered unforeseen events, like a break in the aqueduct of the university the day before the event. Despite all constraints, obligations and mishaps, it is important to be flexible. The show must go on. 


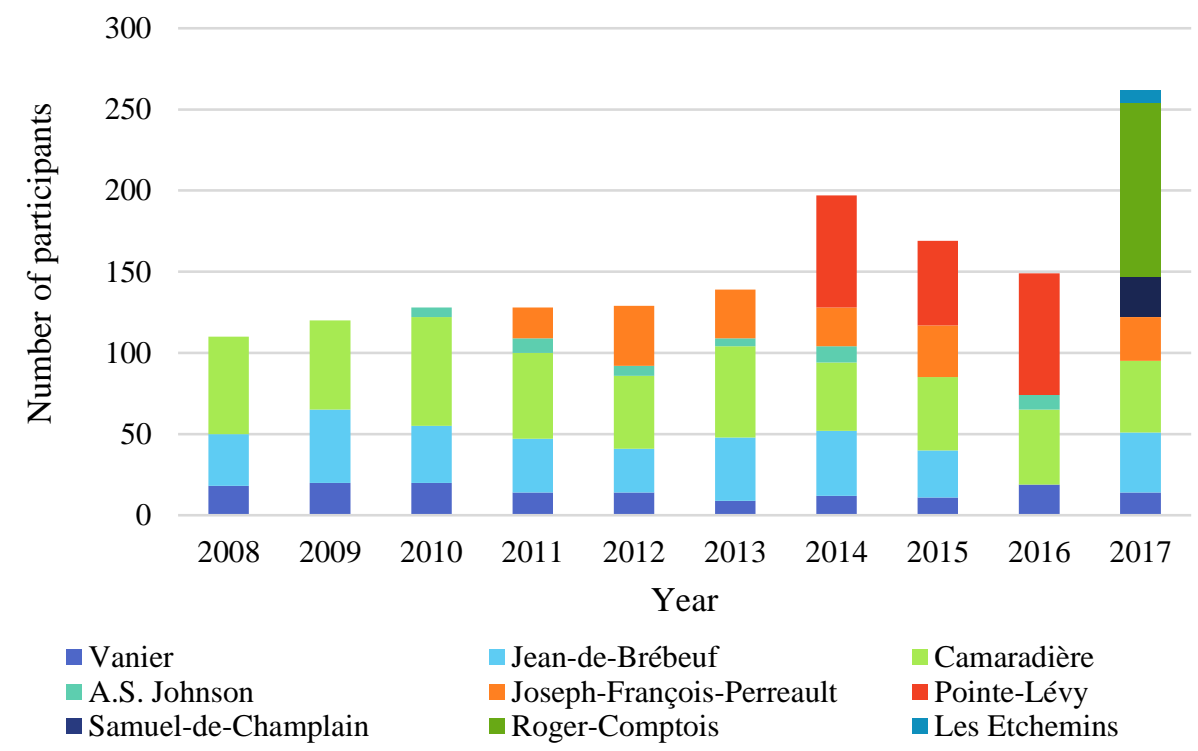

Figure 2. Number of participants per school per year

Since one of the main goals of the Photonic Games is to increase STEM-related self-confidence among students from underprivileged communities by involving them in a fun and positive activity, we have always targeted schools from areas with specific socio-economic backgrounds. To select new schools, we have often used the Low Income Index (SFR) related to family revenue with respect to poverty threshold and the Socio-Economic Index (IMSE), accounting for the level of education and the employment situation in the student's family. Both indexes are reported on a scale from 1 to 10, depending on their percentile rank in the province (1 representing the most privileged socio-economic background). While not all schools participating in the Photonic Games have high indexes, Vanier, Jean-de-Brébeuf and Joseph-FrançoisPerreault schools had a (SRF, IMSE) of $(10,10),(10,9)$ and $(9,7)$ respectively, as of 2017 [3]. Considering all the students that participated in the Photonic Games since 2008, the average (SFR, IMSE) for the activity is $(7.25,5.15)$.

\section{Lesson \#6: Collect small victories}

In the first years, we dealt with a lot of absenteeism and a few negative student leaders attending the activity, especially from the most underprivileged schools of the area. At some point, we started wondering if we were reaching our goals. Thanks to positive comments from the teachers about their students' motivation after the activity, we were convinced that we were on the right track. In 2013, a participant from Vanier High School, located in one of the most underprivileged neighborhoods of the province, said: "The day was perfect, diverse activities, I would do it again". This is just one example. Over the years, there have been more and more of these comments that have strengthened our desire to continue to pursue the same goals.

\section{10 YEARS OF HEALTHY COMPETITION}

Despite goals being unrelated to performance, the Photonic Games remain a competition. The top 3 teams for each challenge are unveiled at the end of the day, followed by the top 3 winning teams of the event. Prizes are given to the winning teams of each challenge and to the overall top 3 teams. This moment is very important, and the sequence of events helps us to reach our goals. By announcing the top 3 teams of each challenge, we make sure that as many students as possible are highlighted. With the support of the many volunteers, we make this moment as festive as possible so everyone has a good time. Even if a team did not get named for the quality of its performance, we encourage students to be happy of the success of other members of their school and to be proud to be part of that group of students. 


\section{Lesson \#7: Creating the priceless feeling of being in the moment}

In the early years, we were able to award great prizes such as laptops. However, we soon realized that the satisfaction and pride that come with a good performance, the joy of receiving a small gift, the feeling of belonging to your team and school and sometimes, the astonishment of the quality of your work compared to others, these are the most important rewards. The Photonic Games now award smaller science-related prizes and strive to instill positive feelings and attitudes during the closing ceremony. We believe that if the students have a positive experience at the Photonic Games, we are one step closer to reaching our goals.

\section{10 YEARS OF METRICS AND EVALUATION}

Improvement of the activity has always been a top priority for the Photonic Games organization. That is why formal surveys have been conducted among participants and informal surveys have been performed with volunteers and teachers. The first year, the survey asked students to point out their favorite and least favorite challenges and to write any comment related to the activity. From 2010 to 2015, each student filled an after-event survey that evaluated:

- Challenges and workshops from 1 to 10 ( 1 being not fun and 10 being a lot of fun)

- The degree to which specific qualities were important to succeed in the challenges (on a scale from 1 to 10)

- Accompanying volunteer (on a scale from 1 to 10 )

- Intention to pursue a career in science $(\mathrm{y} / \mathrm{n})$

- Any comments that the student wanted to express

Fig. 3 shows the results of the survey for year 2010 and year 2013, as an example. Most of the challenges got a better score in 2013 than 2010, but it is not possible to draw solid conclusions partly because the concept of 'fun' on which students are surveyed is quite abstract and personal. The results however lead us to think that switching from Jell-Optics to Hit the Target and adding the Laser Chess to the Laser Maze challenge had a positive impact on the overall participant's experience.

The intention of students to pursue a career in science and the potential impact of the activity on this choice is very difficult to evaluate. Firstly, we do not have pre-existing data on their intention to pursue a career in science or not. Following these students over a long period to assess if the Photonic Games made an impact on their career choice would not only take a lot of resources, but would also require complicated procedures and a data management plan. Secondly, the survey represents their intention of pursuing or not a career in science at a specific moment in time. It is not an indicator of their final choice. From the data gathered in 2010 and 2013, we found that respectively $56 \%$ and 54\% of the participants wanted to pursue a career in science after the main event.

\section{Lesson \#8: Not all good metrics are numbers}

"Not everything that can be counted counts, and not everything that counts can be counted." The person who said that was most certainly not referring to metrics, but it applies to it fairly well. Over the years, some participants became volunteers once they started an undergraduate program. One of them mentioned that he was already planning to pursue a career in science before the Photonic Games, but the event awakened him to optics and photonics specifically. He was also happy to see that "the coolest challenge setups were still used". This testimony and many more gathered year after year from various sources are invaluable metrics. 
Jell-Optics (2010) / Hit the Target (2013)

Optical Mini-Putt

Photonics Quiz

Solar Car Race

Laser Maze (2010) / Laser Maze and Laser Chess (2013)

Photo Contest

Laboratory Tour

Workshop in the classroom

Self confidence

Motivation

Communication

Dexterity

Creativity

Teamwork

Knowledge

Leadership

Accompanying volunteer

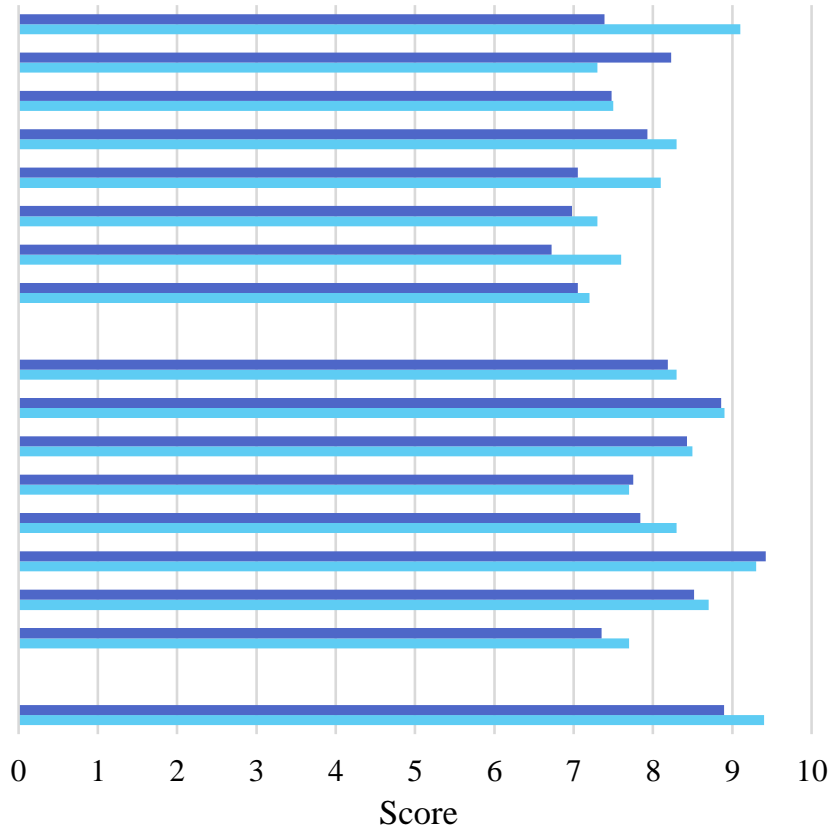

- $2010 \quad$ - 2013

Score

Figure 3. Results of survey among participants for years 2010 (dark blue) and 2013 (light blue)

Since 2016, the organization has not conducted formal surveys among participants but still gathers information informally but systematically from other sources, mostly the volunteers and teachers. Their intention for the future is to switch from paper surveys to electronic surveys.

\section{10 YEARS OF TEAMWORK}

Teamwork is a central aspect of the Photonic Games. From Fig. 3, it is possible to see that participants consider teamwork the most important quality to succeed at the Photonic Games. High school students go through the challenges in teams, led by a university volunteer. Other volunteers team up to run specific challenges or conduct the workshops in the classroom or the laboratory tours. From the field of optics or not, graduate and undergraduate students work towards the achievement of a common goal to give the best experience possible to the participants. Since 2010, formal documents and training sessions have been developed to help volunteers in achieving a pedagogical and positive approach related to the main goals of the event. We have also witnessed how highly motivated volunteers can completely change the experience and the mind-set of the participants.

\section{Lesson \#9: One for all and all for one}

When brainstorming about the lessons learnt from 10 years of Photonic Games, all past presidents pointed out that the people and their team spirit had been the most powerful resource. In 2012, we dealt with almost no members from the 2011 organizing committee returning. The idea of not having Photonic Games that year was heartbreaking and, with the leadership of a committee member and new volunteers, the activity took place. From setting up the first edition to dealing with difficulties or increasing the number of participants, the volunteers always made it possible. They also gave great feedback on the student's experience, their enthusiasm towards each challenge and often suggested concrete ideas to improve the activity. Finally yet importantly, the direct contact that the high school students have with the university volunteers as allies and partners during the day makes science less impersonal and more approachable. They also have the opportunity to ask questions about optics and photonics, science in general, and college and university training programs. This could not be possible without a large and committed team. 
The format of the Photonic Games also requires a high ratio of volunteers with respect to the number of participants, as seen in a picture from the 2017 edition (Fig. 4). In 10 years, the Photonic Games have also been an opportunity for organizers and volunteers to expand their network. Now working in industry, past members of the organizing committee have returned to the event to represent their company that is sponsoring the event.

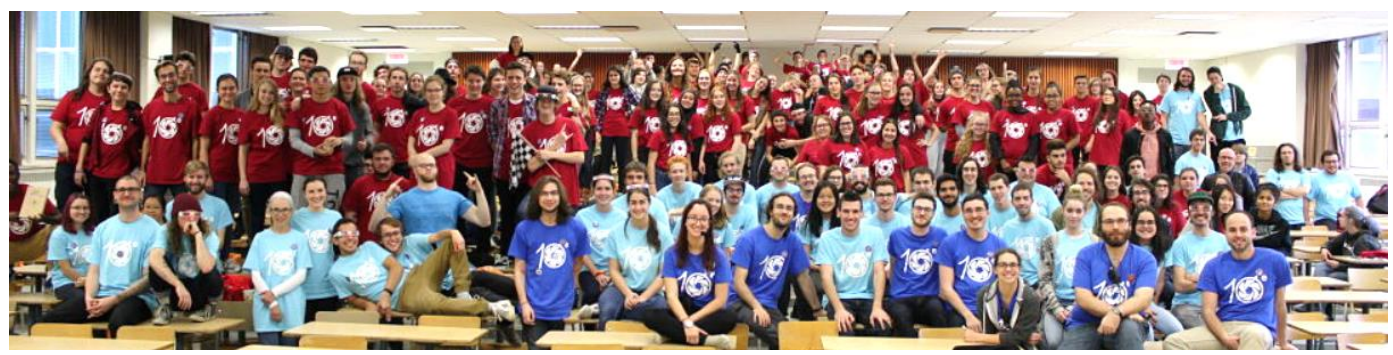

Fig. 42017 participants (in red), a number of volunteers (in light blue) and members of the organizing team (in dark blue) for one of the two days of the event

\section{10 MORE YEARS TO COME, CONSTANTLY PREPARING THE FUTURE}

The Photonic Games are a student-led organization in which, like most student organizations, changeover is known to be challenging. Taking heed of other student-led activities from Université Laval, the organizing committee now includes one or more VPs-in-waiting. VPs-in-waiting are committed to being members of the organizing committee for at least two years and do not have dedicated tasks in their first year. They are helping the other VPs with their duties and learning about the ins and outs of the activity. This mechanism ensures a certain stability and continuity to the organization.

\section{Lesson \#10: The future has already begun}

In French, there is a saying that translates as "If you want something done right, you better do it yourself". Despite that, one past president mentioned that the Photonic Games made her realize how relying on people that you trust is sometimes mandatory and can lead to grand results. Whether it is learning to trust newcomers or taking the time to teach someone how to do something even if it would be quicker to do it yourself, our task as organizers is not only to manage a great activity, but also to prepare for the future. That is the key to longevity.

In 10 years, more than 100 organizers and 425 volunteers gave their best effort to promote optics and photonics and improve the self-confidence of 1531 grade 11 students from 9 high schools in our area. Above all the lessons learnt and highlighted in these proceedings, all past presidents agree that their experience with the Photonic Games has been an opportunity to grow and learn. By investing energy and countless hours in planning and implementing this outreach activity for teenagers, we all got so much more in return.

\section{REFERENCES}

[1] A.-S. Poulin-Girard et al., "Photonic games: hands-on challenges to spark teenagers' interest in light," Proc. SPIE 7783, Optics Education and Outreach, 77830A (30 August 2010).

[2] V. Zambon, G. Thériault, A.-S Poulin-Girard, "Outreach facilities within a research center," Proc. SPIE 8481, Optics Education and Outreach II, 84810 O (15 October 2012).

[3] Ministère de l'éducation et de l'enseignement supérieur du Québec. (2017). Indices de défavorisation des écoles publiques, 2016-2017 : Écoles primaires et secondaires. http://www.education.gouv.qc.ca/references/indicateurs-etstatistiques/indices-de-defavorisation/ (in French only) 